\title{
Yttrium-90 ibritumomab tiuxetan in the treatment of non-Hodgkin lymphoma
}

\author{
Matthew S McKinney \\ Anne W Beaven \\ Division of Hematologic Malignancies, \\ Department of Medicine, Duke \\ University Medical Center, Durham, \\ NC, USA
}

This article was published in the following Dove Press journal:

Blood and Lymphatic Cancer:Targets and Therapy

16 August 2014

Number of times this article has been viewed

\begin{abstract}
Most cases of indolent non-Hodgkin lymphoma (NHL) are incurable with standard chemoimmunotherapy approaches, and patients with relapsed/refractory disease have progressively shorter remissions and short survival with subsequent chemotherapy regimens. This may potentially be overcome with diversification of treatment strategies to include other modalities including radiotherapy, small molecule signaling transduction inhibitors, or highdose chemotherapy with stem cell support. Yttrium-90 ibritumomab tiuxetan $\left(\right.$ Zevalin $\left.^{\circledR}\right)$ is a novel treatment entity for indolent NHL. A radiolabeled antibody conjugate, it consists of a murine anti-CD20 antibody linked to a chelator molecule, tiuxetan, which is bound to radioactive yttrium. Yttrium-90 ibritumomab tiuxetan is approved for use as consolidation after initial treatment of follicular lymphoma as well as single-agent therapy in relapsed/refractory B-cell NHL. Responses are seen even in patients refractory to conventional cytotoxic chemotherapy and rituximab in both indolent and aggressive NHL subtypes. Recent clinical studies have also shown that yttrium-90 ibritumomab tiuxetan has significant activity when combined with novel targeted small molecular inhibitors as well as in autologous and allogeneic transplantation regimens. Here we review the biology underlying the efficacy of yttrium-90 ibritumomab tiuxetan in NHL and present an overview of the clinical experience with this agent in NHL. Finally, we discuss the current role of yttrium-90 ibritumomab tiuxetan in the armamentarium of treatments for NHL and possibilities for incorporating it into future NHL treatment algorithms.
\end{abstract}

Keywords: non-Hodgkin lymphoma, indolent, CD20, radioimmunotherapy, ibritumomab tiuxetan

\section{Introduction}

According to the Surveillance, Epidemiology and End Results program data, non-Hodgkin lymphoma (NHL) is the sixth leading cause of cancer death in the USA. ${ }^{1}$ Accounting for roughly 80,000 new diagnoses each year, ${ }^{1} \mathrm{NHL}$ is a heterogeneous group comprising dozens of different lymphomas that can be broadly grouped into indolent or aggressive subtypes, both of which are primarily treated with chemotherapy-based regimens. ${ }^{2}$ Over half of these lymphomas are indolent B-cell lymphomas, which follow a relapsing and remitting course for which symptomatic patients will receive treatment intermittently for many years. ${ }^{3}$ With successive treatments, the durability of response and survival time in indolent NHL decreases substantially. ${ }^{4}$ Similarly poor outcomes are seen in relapsed/ refractory aggressive NHL. In aggressive NHL, while the goal of treatment is generally cure of the disease, less than half of patients with high-risk aggressive NHL subtypes, such as diffuse large B-cell lymphoma (DLBCL), will achieve a cure with standard chemoimmunotherapy approaches. ${ }^{5-7}$ Thus, the development and use of effective, alternative approaches to treatment for patients in the relapsed/refractory setting is essential.

Correspondence: Anne W Beaven Division of Hematologic Malignancies, Department of Medicine, Duke University Medical Center, Box 3382, Durham, NC 277I0, USA

Email anne.beaven@dm.duke.edu
Blood and Lymphatic Cancer: Targets and Therapy 20I4:4 45-59 cc) (i) (5) 2014 Mckinney and Beaven. This work is published by Dove Medical Press Limited, and licensed under Creative Commons Attribution - Non Commercial (unported, v3.0) LY LC License. The full terms of the License are available at http://creativecommons.org/licenses/by-nd/3.0/. Non-commercial uses of the work are permitted without any further permission from Done how to request permission may be found at: http://www.dovepress.com/permissions.php 
Yttrium-90 (Y90) ibritumomab tiuxetan is an antibodydrug conjugate targeting CD20 and has been investigated as a treatment for NHL in both the front-line and relapsed/ refractory settings. Greater than $85 \%$ of NHL cases arise from B-cells with high levels of CD20 expression, allowing the majority of lymphomas to be targeted with Y 90 ibritumomab tiuxetan. This agent is approved by the US Food and Drug Administration (FDA) for use as consolidation after initial treatment of follicular lymphoma as well as single-agent therapy in relapsed/refractory B-cell NHL. While the clinical utility of Y90 ibritumomab tiuxetan has been studied in hundreds of clinical trials covering a wide range of NHL subtypes and clinical situations, its current role in the treatment of NHL is not well defined, and some investigators argue that $\mathrm{Y} 90$ ibritumomab tiuxetan is underused. Herein, we review the development of Y90 ibritumomab tiuxetan, clinical data supporting its use and possible reasons for its low utilization, and explore the current state of the clinical data regarding its use in other NHL subtypes.

\section{Rationale for use}

CD20-targeted antibodies work through multiple mechanisms, including direct interruption of receptor-ligand signal transduction, mediation of complement-dependent cytotoxicity, and antibody-dependent cellular cytotoxicity. ${ }^{8}$ CD20 antibodies thus result in tumor cell death by modes distinct from those involved in the response to cytotoxic chemotherapy. They also essentially spare CD20-negative tissues from side effects. For example, very few side effects were seen in early phase clinical trials of rituximab, the first anti-CD20 monoclonal antibody to receive FDA approval. ${ }^{9,10}$ Further clinical studies have shown that, when given as part of standard induction chemotherapy for the two most common forms of NHL, ie, DLBCL and follicular lymphoma, rituximab improves overall survival and progressionfree survival. ${ }^{11,12}$ More prolonged use in maintenance/ consolidation schemas employing rituximab improved overall survival in mantle cell lymphoma (MCL) ${ }^{13}$ and progressionfree survival in follicular lymphoma. ${ }^{14}$

To further capitalize on CD20 expression in NHL and take advantage of the sensitivity of lymphomas to radiation, ${ }^{15}$ radiolabeled CD20 antibodies such as ibritumomab tiuxetan were developed. These antibodies deliver radioisotopes directly to the tumor cells by targeting the specific cell surface antigen, CD20. After binding CD20, the radioisotope moieties are internalized and emit toxic ionizing radiation within the tumor cell. ${ }^{16} \mathrm{Y} 90$ ibritumomab tiuxetan (Zevalin ${ }^{\circledR}$; Idec Pharmaceuticals, Corporation, San Diego, CA, USA) is a unique CD20-radiolabeled antibody-drug conjugate and has been studied extensively in multiple Phase I-III clinical trials in NHL. Based on these studies, Y90 ibritumomab tiuxetan was approved by the FDA for the treatment of relapsed/ refractory indolent B-cell lymphoma and for consolidation therapy in follicular lymphoma responding to initial treatment with chemotherapy. ${ }^{17}$

\section{Structure and administration}

Ibritumomab is a monoclonal mouse immunoglobulin $G_{1}$ antibody that serves as the variable component of the chimeric antibody rituximab. It binds CD20 with high affinity at nanomolar concentrations and can elicit antibody-dependent cellular cytotoxicity or complement-dependent cytotoxicity effectively. The ibritumomab is bound to tiuxetan, a small molecule chelator agent that can bind multiple radioisotopes. Ibritumomab tiuxetan is then conjugated to Y90, the radioactive component, which provides much of the clinical benefit.

The specificity afforded by targeting Y 90 to CD20+ tissues results in an approximately 800 -fold higher radiation dose to CD20+ lymphoma tissue as compared with normal tissues. ${ }^{18}$ Although the radiation emitted is able to penetrate to some degree into the surrounding tissues, this effect is small because $\mathrm{Y} 90$ ibritumomab tiuxetan emits beta particles at an energy of $2.3 \mathrm{MeV}$ and a penetration of only $5-10 \mathrm{~mm}$. This degree of collateral radiation scatter may increase efficacy in states of bulky disease or compromised vascular distribution while avoiding unnecessary toxicity. In order to fully assess this hypothesis, for many years dosimetry was performed, prior to administering the therapeutic Y90 ibritumomab tiuxetan, to evaluate off-target radiation exposure to nearby normal tissue. ${ }^{18-20}$ Since $\mathrm{Y} 90$ is a pure beta emitter, it cannot be detected externally by imaging devices; therefore, several days prior to treatment, patients were administered indium-111 ibritumomab tiuxetan, which can be imaged by measurement of gamma radiation. Indium-111-based dosimetry in these studies demonstrated that acceptable off-target radiation exposures are seen at the therapeutic dose of Y 90 ibritumomab tiuxetan. Ibritumomab tiuxetan dosimetry with indium-111 was used widely in clinical practice in the USA until an analysis of dosimetry data by Wiseman et al from four clinical trials involving 179 patients showed that dosimetry and dose adjustment would not change the administered dose compared with body surface area-based dosing alone in the majority of cases. ${ }^{21}$ Therefore, the requirement for indium-111 was removed from the product label in 2011, and a fixed dosing scheme is employed by most centers. 
In order to improve exposure of lymphoma cells to Y90 ibritumomab tiuxetan is given after initial dosing with rituximab to reduce the level of normal CD20+ B-cells. Administration of rituximab prior to radiolabeled antibody-conjugate infusion improved dosimetry visualization of known disease in the initial Phase I study, presumably by depleting competing normal circulating and lymph node CD20+ B-cells prior to radioimmune conjugate treatment.

In Phase I trials, $0.4 \mathrm{mCi} / \mathrm{kg}$ was found to be the maximum tolerated dose for Y 90 ibritumomab tiuxetan when given as a single agent in patients with a normal platelet count. ${ }^{22,23}$ Thrombocytopenia is the most frequent grade 4 hematologic toxicity complicating Y90 ibritumomab tiuxetan treatment. A Phase II trial exploring treatment with reduced dose ( 0.3 $\mathrm{mCi} / \mathrm{kg}$ ) Y90 ibritumomab tiuxetan in NHL patients with platelet counts of $100,000-150,000 \mu \mathrm{L}$ showed tolerability in this patient population. ${ }^{24}$ It is not used in patients with platelet counts lower than $100,000 \mu \mathrm{L}$. Since cytopenias are the most profound toxicity and the radiation from Y 90 can have some impact on surrounding tissue, it is not used in patients with $\geq 25 \%$ lymphoma seen on bone marrow biopsy prior to treatment. Doses up to $1.2 \mathrm{mCi} / \mathrm{kg}$ have been used as the sole preparative regimen for allogeneic hematopoietic stem cell transplantation with tolerable non-hematopoietic dosimetry and toxicity profiles, but this is likely the upper limit of dosage tolerable to non-hematopoietic tissues and is not used outside of the clinical trial setting..$^{25}$

In summary, the current labeling states that Y90 ibritumomab tiuxetan may be given at a dose of $0.4 \mathrm{mCi} / \mathrm{kg}$ to subjects with a normal platelet count, and this dose is adjusted to $0.3 \mathrm{mCi} /$ $\mathrm{kg}$ if the baseline platelet count is $100,000-150,000 / \mu \mathrm{L}$, with a maximum allowable dose of $32 \mathrm{mCi}$. No dosimetry-based adjustments are needed, and rituximab $250 \mathrm{mg} / \mathrm{m}^{2}$ is administered on days 1 and 8 of a treatment scheme with Y 90 ibritumomab tiuxetan infusion given immediately after the second dose of rituximab (Figure 1). Similar dosing schemas have been studied in hundreds of clinical protocols and retrospective series, largely in indolent subtypes of NHL.

\section{Toxicities}

Ytrium-90 ibritumomab tiuxetan is extremely well tolerated. Most of the toxicities seen in Phase I trials (Table 1) were hematologic, with a median granulocyte nadir of $1.1 \times 10^{9} \mu \mathrm{L}$ (baseline $4.0 \times 10^{9} \mu \mathrm{L}$ ), and median platelet nadir of $49.5 \times 10^{9} \mu \mathrm{L}$ (baseline $226 \times 10^{9} \mu \mathrm{L}$ ) in the first standard-dose Phase II study. ${ }^{23}$ An overview of these studies is depicted in Table 1. Notably, development of cytopenias after radioimmunotherapy (RIT) occurs at 4-6 weeks post

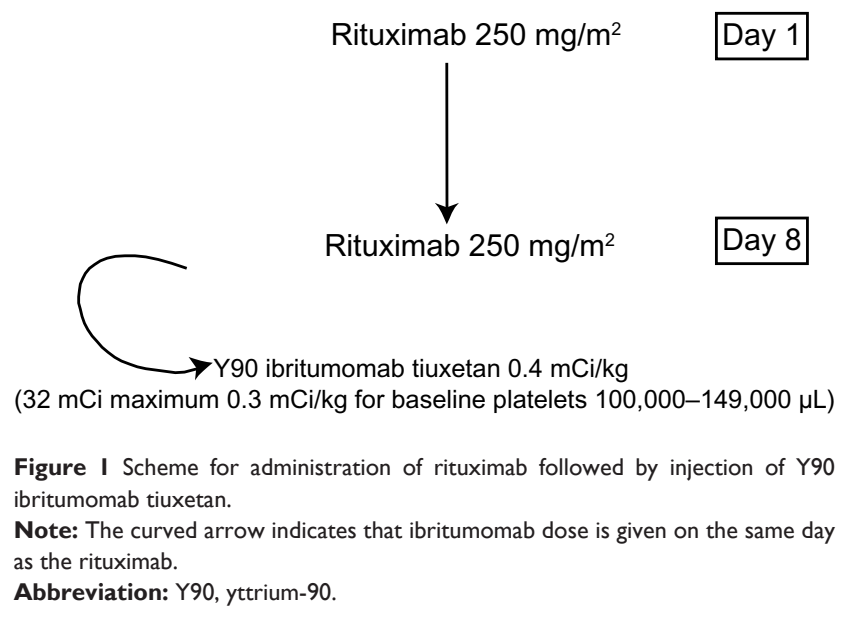

treatment, with recovery $9-20$ days after nadir, which is later than what is typically noted after cytotoxic chemotherapy for NHL. ${ }^{22,23}$ The degree of cytopenia appears to be dependent upon the baseline blood counts at the time of treatment as well as the number of previous chemotherapy regimens, although safety with standard dosing after myeloablative hematopoietic stem cell transplantation has been demonstrated. ${ }^{23,26,27}$

Given the penetration of ionizing radiation from Y 90 into normal tissue, and its pronounced effect on the bone marrow, a prominent concern with Y 90 ibritumomab tiuxetan is the risk of developing treatment-related myeloid malignancies. Two data sets illuminate this issue. Czuczman et al reported a retrospective study of data from 746 patients treated with Y90 ibritumomab tiuxetan at multiple centers with a median follow-up of 4.5 years. ${ }^{28}$ Nineteen patients $(2.5 \%)$ were diagnosed with treatment-related myelodysplastic syndrome (MDS) or acute myeloid leukemia (AML) within a median of 1.9 years from administration of RIT, and a $0.7 \%$ per year rate of treatment-related MDS/AML was calculated from time of RIT. The majority of cases of treatment-related MDS/AML had recurrent cytogenetic abnormalities linked to previous treatment with radiation and/or alkylator-based chemotherapy. Since these patients had also received multiple other lines of radiation and chemotherapy, it is impossible to determine the individual contribution of RIT versus prior chemotherapy exposure to the development of MDS/AML. ${ }^{28}$

Long-term data after RIT's use in the front-line setting more clearly suggest an increased incidence of MDS/AML in subjects who received RIT. After a median follow-up of 7.3 years, data from the randomized First Line Indolent (FIT) trial reported by Morschhauser et al showed that seven of 201 (actuarial 8-year incidence of 4.2\%) patients treated with RIT consolidation developed treatment-related 
Table I Toxicities from key multicenter clinical trials evaluating single-agent $Y 90$ ibritumomab tiuxetan in relapsed/refractory nonHodgkin lymphoma (rows I and 2) and consolidation with Y90 ibritumomab tiuxetan after response to induction chemotherapy

\begin{tabular}{|c|c|c|c|c|c|}
\hline Reference & Design & Patients (n) & $\begin{array}{l}\text { Y90 ibritumomab } \\
\text { tiuxetan dosing }\end{array}$ & $\begin{array}{l}\text { WBC nadir } \\
\text { (baseline, } \mu \mathrm{L} \text { ) }\end{array}$ & $\begin{array}{l}\text { Platelet nadir } \\
\text { (baseline, } \mu \mathrm{L} \text { ) }\end{array}$ \\
\hline Knox et $\mathrm{a}^{22}$ & Phase I & 18 & $\begin{array}{l}\text { 3-4 patients per cohort treated } \\
\text { with dose levels } 13.5,20,30,40 \text {, and } \\
50 \mathrm{mCi} / \mathrm{kg} \text { Y } 90 \text { ibritumomab tiuxetan }\end{array}$ & $1.7(5.6)$ & $40(177)$ \\
\hline Witzig et $\mathrm{a}^{23}$ & Phase I & 15 & $0.4 \mathrm{mCi} / \mathrm{kg}$ Y 90 ibritumomab tiuxetan & $\begin{array}{l}\text { I.I (4.0) granulocyte } \\
\text { count }\end{array}$ & $49.5(226)$ \\
\hline $\begin{array}{l}\text { Morschhauser } \\
\text { et } \mathrm{al}^{29}\end{array}$ & Phase III & $\begin{array}{l}409 \text { ( } 204 \text { Y } 90 \\
\text { ibritumomab } \\
\text { tiuxetan treated) }\end{array}$ & $\begin{array}{l}\text { Chemotherapy followed by } \\
0.4 \mathrm{mCi} / \mathrm{kg} \text { Y } 90 \text { ibritumomab tiuxetan }\end{array}$ & NR & NR \\
\hline
\end{tabular}

Abbreviations: G-CSF, granulocyte colony-stimulating factor; NR, not reported; RIT, radioimmunotherapy; WBC, white blood cell count; Y90, yttrium-90.

MDS/AML versus one case in 202 (actuarial 8-year incidence of $0.6 \% ; P=0.042$ ) patients in the comparator arm who received standard chemotherapy without RIT. The median time from randomization to diagnosis of MDS/AML was 57 (range 22-84) months. Therefore, there may be an excess of treatment-related myeloid malignancies in patients treated with Y 90 ibritumomab tiuxetan as compared with similarly treated patients with NHL not receiving RIT. $^{29}$

An additional pragmatic consideration is the tolerability and efficacy of other treatments, including chemotherapy, high-dose chemotherapy, and stem cell rescue or radiotherapy administered around the time of Y90 ibritumomab tiuxetan. The question of chemotherapy dosing and toxicity post RIT was addressed by an analysis of patients treated in early clinical protocols at the Mayo Clinic and reported by Ansell et al. In a cohort of 58 patients treated with cytotoxic chemotherapy administered after completion of Y90 ibritumomab tiuxetan, toxicities were similar to those in similarly treated control groups not treated with RIT; additionally, eight patients in this study went on to successful hematopoietic stem cell collection after RIT. ${ }^{27}$

\section{In front-line treatment of follicular lymphoma}

In 2009, Y90 ibritumomab tiuxetan was approved by the FDA for use as consolidation in patients with previously untreated follicular lymphoma who have a partial response or a complete response (CR) to initial chemotherapy. Prior to its approval, the only maintenance approach used in indolent lymphoma was intermittent rituximab every 2, 3, or 6 months. ${ }^{14,30,31}$ While this demonstrated improved progression-free survival compared with observation, it required up to 2 years of additional treatment. RIT is an attractive alternative form of consolidation because it is effective and convenient, with treatment given over a period of 1-2 weeks versus 2 years with conventional anti-CD20 antibodies.

Y90 ibritumomab tiuxetan has been evaluated as consolidation post chemotherapy in one randomized Phase III clinical trial, ie, FIT. In this study, Morschhauser et al randomized 207 patients with follicular lymphoma and documented CR/unconfirmed CR (Cru) or partial response after initial chemotherapy to Y90 ibritumomab tiuxetan $14.8 \mathrm{MBq} / \mathrm{k}$ or observation. ${ }^{29,32}$ A variety of chemotherapy programs were used in this study, including CVP (cyclophosphamide, vincristine, and prednisone), CHOP (cyclophosphamide, doxorubicin, vincristine, and prednisolone), chlorambucil and fludarabine, but only $13.2 \%$ of the RIT arm and $15.6 \%$ of the control arm received rituximab as part of their initial induction chemotherapy regimen. Post-chemotherapy rituximab maintenance schemes were not allowed in either arm. Progression-free survival in the overall patient cohort was 36.5 months in the Y90 ibritumomab tiuxetan arm versus 13.3 months with observation alone $(P<0.001)$. More substantial differences were seen in outcomes between arms in patients in partial response at time of enrollment where progression-free survival was 29.3 versus 6.2 months (Y90 ibritumomab tiuxetan versus observation; $P<0.0001)$. However, even patients in a $\mathrm{CR} / \mathrm{Cru}$ at the time of randomization had an increased progression-free survival with RIT (29.5 versus 53.9 months, $P=0.0154$ ). In addition, $78 \%$ of the patients with a partial response at study enrollment converted to a CR after RIT versus only $17.5 \%$ in the control $\operatorname{arm}(P=0.001)$ suggesting that $Y 90$ ibritumomab tiuxetan may deepen the response when used with chemotherapy. In longterm follow-up reported in 2013, the median time to next treatment was 8.1 years for $Y 90$ ibritumomab tiuxetan versus 3.0 years in the control arm. Both cohorts had an approximately $80 \%$ response rate to retreatment with chemotherapy at time of first progression. ${ }^{29,32}$ RIT consolidation in this study was well tolerated with the expected increase in hematologic toxicities. 


\begin{tabular}{|c|c|c|c|c|c|}
\hline $\begin{array}{l}\text { Neutrophil } \\
\text { nadir time }\end{array}$ & $\begin{array}{l}\text { Platelet } \\
\text { nadir time }\end{array}$ & $\begin{array}{l}\text { Grade 3/4 } \\
\text { granulocytopenia }\end{array}$ & $\begin{array}{l}\text { Grade } \\
\text { 3/4 anemia }\end{array}$ & $\begin{array}{l}\text { Grade } 3 / 4 \\
\text { thrombocytopenia }\end{array}$ & Comments \\
\hline 5.I weeks & 4.8 weeks & $72.20 \%$ & $22.20 \%$ & $77.80 \%$ & $\begin{array}{l}3 / 4 \text { patients at } 40 \mathrm{mCi} \\
\text { dose received } \mathrm{G}-\mathrm{CSF}\end{array}$ \\
\hline 50 & 43 & NR & NR & NR & $\begin{array}{l}3 \text { patients received G-CSF, } \\
10 \text { patients received } \\
\text { platelet transfusion }\end{array}$ \\
\hline NR & NR & $66.70 \%$ & $3.40 \%$ & $60.80 \%$ & $\begin{array}{l}\text { Phase III consolidation } \\
\text { study, RIT given to } \\
\text { responders post induction }\end{array}$ \\
\hline
\end{tabular}

Grade $3 / 4$ neutropenia occurred in $66.7 \%$ versus $2.5 \%$ in the control arm. The median time to neutrophil nadir was 44-46 days, with a median recovery time of 20 days for grade 3 and 28 days for grade 4 neutropenia. Grade 3/4 infection occurred in $7.9 \%$ versus $2.4 \%$ in the controls. Similarly, grade $3 / 4$ thrombocytopenia occurred in $60.8 \%$ of subjects on the RIT arm versus in none of the controls. Platelet nadir occurred a little earlier than neutropenia with nadir at 35 days for grade 3 and 39 days for grade 4 thrombocytopenia. Median time to platelet recovery was 20 days and 35 days for the respective grades. There were more grade 3/4 non-hematologic adverse events in the RIT arm (29\% versus 19\%), mostly infection, pyrexia, and hypertension..$^{29,32}$

Based on the results of the FIT trial, Y90 ibritumomab tiuxetan was approved by the FDA for consolidation after initial chemotherapy in follicular cell NHL. However, its ultimate role in this situation is not yet clear, since the data suggest that it may increase the incidence of MDS/AML compared with observation. In addition, randomized data are lacking to compare it with maintenance rituximab or even to look at its benefit after prior rituximab-containing regimens since less than $20 \%$ of subjects had previously received rituximab.

While Y90 ibritumomab tiuxetan is not approved by the FDA for single-agent use as initial therapy in indolent NHL, there are data suggesting that it may have a role in this setting as well. Scholz et al reported 30-month follow-up from a multicenter Phase II trial in Europe that enrolled 59 patients with stage II-IV follicular lymphoma requiring treatment. Eighty-seven percent of patients responded, with $56 \%$ attaining a CR after 6 months of treatment. In this trial, the median progression-free survival for all subjects was 25.9 months and had not been reached for those in a CR. In addition, as seen in other RIT trials, those patients still with a CR at 12 months had very durable responses, with relapses seen in only three of 26 patients at the time of the report. Not surprisingly, there appeared to be a trend towards shorter progression-free survival in patients with elevated lactate dehydrogenase levels or higher $(\geq 2)$ Follicular Lymphoma International Prognostic Index scores, suggesting patients with more aggressive disease may require more intensive chemotherapy-based induction treatment rather than single-agent RIT. ${ }^{33}$

A fractionated scheduled of Y90 ibritumomab tiuxetan as front-line therapy for follicular lymphoma has also been studied in an attempt to further deepen the response. Treatment consisted of two 11.1 MBq/kg doses of RIT scheduled 8-12 weeks apart. This scheme was designed with the rationale that initial debulking of disease would improve rates of response to administration of a second dose of RIT. In cases where count recovery was delayed, an additional 4 weeks of recovery time was allowed. Seventy-four patients with follicular lymphoma and less than $20 \%$ bone marrow involvement who required treatment according to Groupe d'Etude des Lymphomes Folliculaires/British National Lymphoma Investigation criteria were enrolled. In patients with $\geq 20 \%$ follicular lymphoma involvement on bone marrow biopsy, four weekly doses with four doses separated by one week each were administered followed by repeat bone marrow examination to determine if the study inclusion criteria were met prior to study involvement. Responses similar to those in other studies of front-line RIT in follicular lymphoma were noted in this trial, with an overall response rate of $94.4 \%$ and a $\mathrm{CR} / \mathrm{Cru}$ of $58.3 \%$ after initial RIT. With the repeat dose, this increased to an overall response rate of $95.8 \%$ and a CR rate of $69.4 \%$. Three-year progression-free survival was estimated to be $58 \%$ and 3-year overall survival was $95 \%$. Sixteen percent of subjects did not receive the second dose of RIT because of prolonged cytopenias, and the incidence of cytopenias was higher after the second dose of RIT. Grade 3/4 thrombocytopenia occurred in $20.8 \%$ of subjects after the first RIT and in $56 \%$ after the second RIT. The duration of thrombocytopenia was longer 


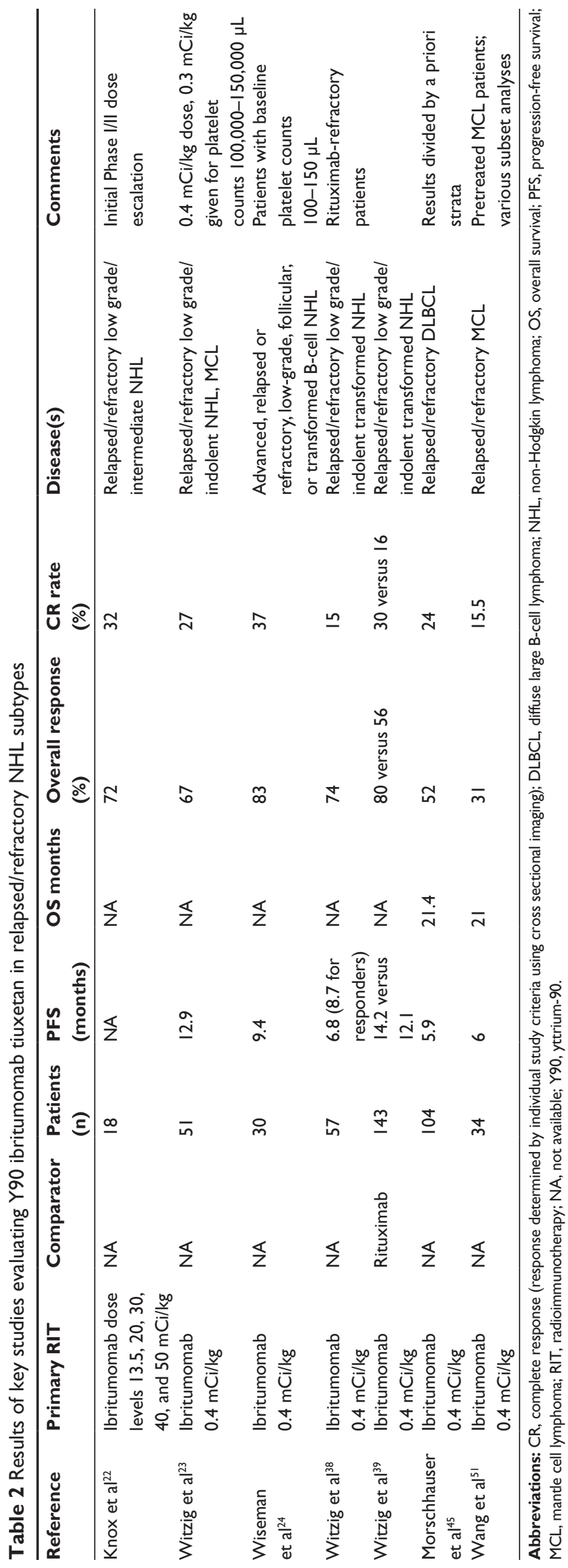

after the second treatment (median 20 days versus 40 days). Grade 3/4 neutropenia was similarly affected, with $20.8 \%$ initially up to $36 \%$ after the second injection, and median duration of neutropenia increased from 18 days to 31 days. No non-hematologic Grade 3/4 toxicities occurred in more than $3 \%$ of patients enrolled. ${ }^{34}$

Taken together, these studies show the efficacy and feasibility of using Y90 ibritumomab tiuxetan as the sole therapy for previously untreated follicular lymphoma. In these studies, RIT was associated with high response rates, especially when considering conversion to $\mathrm{CR} / \mathrm{Cru}$ over the initial 6-12 months. These trials had response rates and outcomes comparable with those in studies of front-line induction immunochemotherapeutic approaches. However, direct comparisons between front-line RIT and front-line rituximab with/without chemotherapy have not been carried out in a prospective randomized manner, so the role of RIT as a single agent for induction therapy in follicular lymphoma in the rituximab era is unclear. Further prospective, randomized controlled trials with longer follow-up are needed to better evaluate the potential of RIT as monotherapy for indolent lymphoma in the front-line setting.

\section{In relapsed/refractory $\mathbf{N H L}$}

Y90 ibritumomab tiuxetan was initially approved for use in patients with relapsed/refractory indolent B-cell NHL (see Table 2). Due to the incurable nature of the indolent lymphomas, affected patients require intermittent treatment with non-cross-resistant therapies. Given that cytotoxic chemotherapies appear to lose efficacy with subsequent rounds of treatment ${ }^{35}$ different approaches with high response rates in relapsed/refractory NHL are needed. Its unique properties as a radioimmunoconjugate make $\mathrm{Y} 90$ ibritumomab tiuxetan an exciting approach.

The initial Phase I studies evaluating Y90 ibritumomab tiuxetan in relapsed disease found overall response rates of $67 \%-72 \%$, with roughly a third of patients attaining a $\mathrm{CR}$ at dose levels approaching $0.4 \mathrm{mCi} / \mathrm{kg}$. Both studies included patients with low-grade NHL, most of whom had received two or more prior chemotherapy regimens..$^{22,23}$ In the subsequent Phase II study by Witzig et al, ${ }^{23}$ relapsed low-grade NHL histologies had an overall response rate of $82 \%$ with a $26 \% \mathrm{CR}$, but the overall/CR rate was only $43 \% / 29 \%$ for intermediate histologies. Notably, no patients with MCL responded to Y90 ibritumomab tiuxetan in this trial. The median duration of response was 11.7 months, with more than $40 \%$ of patients having durable responses out to 16 months of follow-up. ${ }^{23}$ 
Table 3 Results of key studies evaluating Y90 ibritumomab tiuxetan in aggressive NHL subtypes

\begin{tabular}{|c|c|c|c|c|c|c|c|c|}
\hline Reference & Treatment & $\begin{array}{l}\text { Patient } \\
\text { population }\end{array}$ & $\begin{array}{l}\text { Patients } \\
\text { (n) }\end{array}$ & PFS* & OS* & $\begin{array}{l}\text { ORR } \\
\text { (\%) }\end{array}$ & $\begin{array}{l}\text { CRR } \\
\text { (\%) }\end{array}$ & Comment(s) \\
\hline $\begin{array}{l}\text { Tsimberidou } \\
\text { et al }{ }^{89}\end{array}$ & Ibritumomab & $\begin{array}{l}\text { Richter } \\
\text { syndrome }\end{array}$ & 7 & NA & NA & 0 & 0 & $\begin{array}{l}\text { Case series, no } \\
\text { responses noted }\end{array}$ \\
\hline $\begin{array}{l}\text { Morschhauser } \\
\text { et } \mathrm{al}^{45}\end{array}$ & Ibritumomab & DLBCL & 104 & 5.9 months & 21.4 months & 52 & 24 & $\begin{array}{l}\text { Results divided by a } \\
\text { priori strata }\end{array}$ \\
\hline Zinzani et al ${ }^{47}$ & $\begin{array}{l}\text { Ibritumomab } \\
\text { consolidation/FM }\end{array}$ & DLBCL & 20 & 2 years $(75 \%)$ & 2 years $(95 \%)$ & 100 & 95 & $\begin{array}{l}\text { Elderly front-line } \\
\text { trial }\end{array}$ \\
\hline Wang et $\mathrm{a}^{51}$ & Ibritumomab & $\begin{array}{l}\text { Relapsed/ } \\
\text { refractory MCL }\end{array}$ & 34 & 6 months & 21 months & 31 & 15.5 & $\begin{array}{l}\text { Pretreated MCL } \\
\text { patients; various } \\
\text { subset analyses }\end{array}$ \\
\hline Zinzani et al ${ }^{46}$ & $\begin{array}{l}\text { Ibritumomab } \\
\text { consolidation } \\
\text { R-CHOP }\end{array}$ & DLBCL & 55 & 2 years $(85 \%)$ & 2 years (86\%) & NA & NA & $\begin{array}{l}50 \% \text { of PRs obtained } \\
\text { CRs with RIT }\end{array}$ \\
\hline Yang et $\left.\mathrm{al}\right|^{48}$ & $\begin{array}{l}\text { Ibritumomab } \\
\text { consolidation } \\
\text { R-CHOP }\end{array}$ & $\begin{array}{l}\text { DLBCL bulky } \\
\text { stage I/II disease }\end{array}$ & 21 & 3 years $(75 \%)$ & 3 years $(85 \%)$ & 80.9 & 76.1 & $\begin{array}{l}\text { DLBCL } \\
\text { consolidation no } \\
\text { comparator }\end{array}$ \\
\hline Beaven et $\mathrm{a}^{61}$ & $\begin{array}{l}\text { Ibritumomab } \\
\text { bortezomib }\end{array}$ & $\begin{array}{l}\text { MCL and low- } \\
\text { grade NHL }\end{array}$ & 12 & 6.4 months & $\begin{array}{l}\text { Median } \\
\text { survival } \\
24 \text { months }\end{array}$ & $50 \%$ & $42 \%$ & $\begin{array}{l}4 / 6 \text { patients with } \\
\text { response were } M C L\end{array}$ \\
\hline Smith et a ${ }^{149}$ & $\begin{array}{l}\text { Ibritumomab } \\
\text { consolidation } \\
\text { R-CHOP }\end{array}$ & $\begin{array}{l}\text { MCL previously } \\
\text { untreated }\end{array}$ & 56 & $\begin{array}{l}34.2 \text { months } \\
\text { median FFS }\end{array}$ & 5 years $(73 \%)$ & 82 & 55 & $\begin{array}{l}\text { Eastern Cooperative } \\
\text { Oncology Group } \\
\text { Study EI499 }\end{array}$ \\
\hline Arranz et $\mathrm{al}^{50}$ & $\begin{array}{l}\text { Ibritumomab } \\
\text { consolidation/ } \\
\text { R-HyperCVAD }\end{array}$ & $\mathrm{MCL}$ & 30 & 4 years, $(52 \%)$ & 4 years, $(81 \%)$ & 97 & $\begin{array}{l}77 \text { (intention to } \\
\text { treat) } 96 \% \text { in } \\
\text { patients } \\
\text { completing } \\
\text { treatment }\end{array}$ & $\begin{array}{l}\text { R-HyperCVAD, } \\
\text { Zevalin consolidation }\end{array}$ \\
\hline
\end{tabular}

Notes: *Median PFS or OS, respectively where calculated in the study, percentages calculated at a set period of time are listed as the period of time followed by the PFS/ OS percentage in parentheses.

Abbreviations: CR, complete response; CRR, complete response rate; DLBCL, diffuse large B-cell lymphoma; FFS, failure-free survival; NHL, non-Hodgkin lymphoma; OS, overall survival; PFS, progression-free survival; FM, fludarabine/mitoxanthrone chemotherapy; MCL, mantle cell lymphoma; PR, partial response: RIT, radioimmunotherapy; ORR, overall response rate; R-CHOP, rituximab, cyclophosphamide, doxorubicin, vincristine, and prednisolone; NA, not available; R-HyperCVAD, rituximab, cyclophosphamide, vincristine, doxorubicin, dexamethasone alternating with cytarabine, and methotrexate; Y90, yttrium-90.

As with prior studies, thrombocytopenia was the most frequent adverse event in the relapsed setting. In the Phase I portion of the study by Witzig et al, the baseline platelet count was found to be a strong predictor of degree of thrombocytopenia, given that no patients with baseline platelets $>150 \times 10^{9} / \mathrm{mL}$ developed grade 4 thrombocytopenia but this occurred in $2 / 8$ patients with baseline platelet counts of $100-120 \times 10^{9}$ cells $/ \mathrm{L} .{ }^{23} \mathrm{~A} 0.3 \mathrm{mCi} / \mathrm{kg}$ (32 mCi maximum cap Y90 ibritumomab tiuxetan) dose was thus assessed in a similar Phase II format in 30 mildly thrombocytopenic (platelet count $100,000-150,000 \times 10^{9}$ cells/L) NHL patients, $67 \%$ of whom had bone marrow involvement. Responses were excellent, even at this lower dose. In this cohort, largely comprised of patients with relapsed follicular lymphoma (83\% with a median of two prior therapies), Wiseman et al reported an $83 \%$ overall response rate, with a $\mathrm{CR} / \mathrm{CRu}$ rate of $43 \%$ and a calculated median time to progression of 12.6 months in responders (9.4 months overall). Acceptable toxicity was seen with this dose of Y 90 ibritumomab tiuxetan, even given the baseline thrombocytopenia. The median nadir absolute neutrophil count and platelet count in this study was $0.6 \times 10^{9}$ cells/L and $26.5 \times 10^{9}$ cells $/ \mathrm{L}$, respectively, with $33 \%$ of patients experiencing grade IV neutropenia and $13 \%$ having grade IV thrombocytopenia. As in other RIT studies, non-hematologic toxicities were predominantly mild, with only three grade III non-hematologic toxicities noted (no grade IV non-hematologic toxicity occurred). Thus, the $0.3 \mathrm{mCi} / \mathrm{kg}$ dose of Y90 ibritumomab tiuxetan appears to be safe and efficacious in thrombocytopenic patients with relapsed/refractory indolent NHL. ${ }^{24,36}$

Randomized controlled trials have shown that RIT results in higher response rates than single-agent rituximab in rituximab-naïve patients. In a multicenter randomized trial, Y90 ibritumomab tiuxetan RIT $(0.4 \mathrm{mCi} / \mathrm{kg}$, capped at $32 \mathrm{mCi})$ was compared with rituximab in 143 patients with rituximabnaïve relapsed, refractory, low-grade, or transformed NHL. The overall response rate in the RIT arm was $80 \%$ versus $56 \%$ with rituximab $(P=0.002)$, with a $30 \%$ versus $16 \%(P=0.04)$ 
CR rate. RIT responses were also more durable in this study, with significantly more ongoing responders at 6 and 9 months in the RIT arm. While a significant improvement in freedom from progression or survival was not seen in this trial, it is nevertheless an important study because it established the superiority of RIT versus rituximab with regard to response rate and durability in a randomized fashion.

A pooled analysis of four clinical studies including data from the same centers hosting this trial has been performed to analyze the outcome of long-term responder patients (response $>12$ months) in more detail. This study found long-term responses in 37\% of patients treated with Y90 ibritumomab tiuxetan and $>80 \%$ 5-year overall survival when long-term responders were considered as a group. ${ }^{37}$ Long-term response appeared to be predicted by $\mathrm{CR}$, as this conferred an odds ratio of 7.0 for achievement of long-term response in multivariate analysis (CR/ $\mathrm{CRu}$ comprised $65 \%$ of long-term responders). ${ }^{37}$ An analogous trial in patients with rituximab-refractory NHL showed CR and partial response rates of $15 \%$ and $74 \%$, respectively, with a time to progression of 6.8 months. ${ }^{38}$ Therefore, RIT after rituximab failure is also efficacious, but response rates appear to be lower and may be less durable than in rituximab-naïve patients. These data argue that a sizable proportion of NHL patients may have long-term responses to RIT even after failure of chemotherapy, and responses can even be seen in a high percentage of patients who are additionally rituximab-refractory. ${ }^{38-40}$

Retreatment with RIT after relapse also has efficacy in a subset of NHL patients. Shah et al reported on a series of 18 patients receiving repeat Y90 ibritumomab tiuxetan after an original CR/partial response to RIT followed by relapse. In this study, toxicities were comparable between first and subsequent RIT treatments and the majority of patients responded to retreatment, including 6/10 patients with repeat CR upon the second infusion of Y90 ibritumomab tiuxetan. ${ }^{41}$

Overall, these studies show that Y90 ibritumomab tiuxetan is effective as a single agent for the treatment of relapsed/ refractory NHL. RIT in this population has an acceptable toxicity profile, and durable responses have been noted in a minority of patients. Salvage chemotherapy treatments and high-dose chemotherapy (HDCT) and stem cell transplantation can be administered before and after Y90 ibritumomab tiuxetan, thus arguing for its status as part of the treatment algorithm for relapsed/refractory NHL, particularly in indolent histologies such as follicular lymphoma.

\section{In aggressive NHL subtypes}

The role of RIT in the treatment of aggressive NHL subtypes such as diffuse large B-cell lymphoma and MCL is an area of ongoing investigation. These patients show higher rates of progression and death as compared with those with the typical indolent NHL subtypes, ${ }^{42-44}$ so there is a great need for novel therapies. Studies of RIT as a single-treatment modality in relapsed/refractory aggressive lymphomas have not yielded encouraging results (see Table 3). Treatment with Y90 ibritumomab tiuxetan at the time of relapse was studied in a single-arm Phase II study that enrolled 104 elderly patients not eligible for high-dose salvage therapy and stem cell rescue as reported by Morschhauser et al. ${ }^{45}$ This study classified patients into three strata determined a priori, that included patients who had relapsed after a CR with chemotherapy alone without rituximab (group A1), patients refractory to front-line induction chemotherapy without rituximab (group A2), and patients treated with rituximab chemotherapy (group B). Overall response rates of about $50 \%$ were obtained in patients who had never received rituximab regardless of whether they had primary refractory disease or had relapsed after prior therapy, whereas rituximab-pretreated patients had an overall response rate of only $19 \%$. This relatively poor outcome in patients with progression post rituximab-containing treatment was also reflected in overall survival, with a median overall survival of 4.6 months in the rituximab-treated group versus $>20$ months in those without prior rituximab. Thus, it appears that the response to RIT in DLBCL is greatly diminished in patients with progression after receiving rituximabbased chemoimmunotherapy, and it may not have a role in the treatment of this group of patients.

Three published clinical trials have evaluated the use of Y90 ibritumomab tiuxetan as consolidation therapy after response to initial chemotherapy in DLBCL, and have demonstrated more encouraging results. Consolidation with Y90 ibritumomab tiuxetan after response to $\mathrm{CHOP}$ with or without rituximab (R-CHOP) yielded CR rates of $82 \%-95 \%$, with acceptable toxicity. ${ }^{46-48}$ One intriguing study in this group is the report by Zinzani et al evaluating short-course R-CHOP (four cycles) versus RIT in elderly patients with DLBCL. Fifty-five patients median age 70 years received four cycles of R-CHOP. After R-CHOP, the overall response rate was $89 \%$ (CR 58\%). All patients ( $\mathrm{n}=48$ ) without disease progression received RIT, after which eight additional subjects achieved a remission, with a $\mathrm{CR}$ rate of $73 \%$. After a median follow-up of 18 months, the estimated 2 -year overall survival was $86 \%$. Toxicity with this program was reasonable, with no patient withdrawn from the study due to adverse events. After RIT, the most common adverse events were hematologic, with grade $3 / 4$ neutropenia in $39.5 \%$ and grade $3 / 4$ thrombocytopenia in $48 \%$, and $6 \%$ requiring platelet transfusions. ${ }^{47}$ 
Several trials have also evaluated the activity of Y90 ibritumomab tiuxetan in MCL, both as a front-line consolidation strategy and in relapsed/refractory disease. The Eastern Cooperative Oncology Group 1499 trial evaluated Y90 ibritumomab tiuxetan consolidation in patients with at least stable disease after four cycles of R-CHOP induction. RIT was administered to 50 of 56 eligible patients. After RIT, the $\mathrm{CR} / \mathrm{CRu}$ rate was $55 \%$ versus $20 \%$ after R-CHOP, with 16 patients changing from $\mathrm{PR}$ to $\mathrm{CR} / \mathrm{Cru}$ and three patients with stable disease obtaining a CR/Cru after RIT. The median time to treatment failure was 34.2 months, with an estimated 3-year overall survival of $80 \%{ }^{49}$ The Spanish GELTAMO (Grupo Español de Linfomas y Trasplantes de Médula ósea) group evaluated a similar consolidation strategy administered after R-HyperCVAD induction chemotherapy in 30 patients. In this study, 24 patients completed six cycles of R-HyperCVAD, and Y90 ibritumomab tiuxetan consolidation was administered to 18 complete responders from this group. Four-year failure-free survival and overall survival was 55\% and $87 \%$, respectively; notably, one death occurred because of hematologic toxicity in the RIT consolidation group. However, $38 \%$ of patients who received chemotherapy and Y90 ibritumomab tiuxetan consolidation developed secondary malignancies, thus limiting the applicability of RIT consolidation after intensive induction chemotherapy for MCL. ${ }^{50}$ The ability of RIT to increase the CR rate after less intensive chemotherapy, however, demonstrates that RIT may have an important role as part of consolidation therapy, but randomized trials are needed to confirm these results.

A Phase II trial completed at MD Anderson Cancer Center treated 34 patients with relapsed/refractory MCL (32 of whom had received prior rituximab-containing chemotherapy) using a standard dose of Y 90 ibritumomab tiuxetan and demonstrated an overall response rate of $31 \%$. Event-free survival was 28 months in those with a response to RIT. In subset analysis, patients with non-bulky disease $(<5 \mathrm{~cm})$ and those with a previous CR after induction chemotherapy had statistically significant improvements in event-free survival. ${ }^{51}$

Given the FDA approval of three agents for relapsed/ refractory MCL based on clinical efficacy from recent reports (ibrutinib,,$^{52,53}$ lenalidomide, ${ }^{54-57}$ bortezomib ${ }^{58-60}$ ), an important consideration in this entity is the potential for RIT/novel therapeutic combinations. RIT in combination with bortezomib was evaluated in a Phase I study that included MCL patients. The combination was found to be tolerable, with overall response and CR rates of $80 \%$ and $60 \%$, respectively, which is higher than reported previously for either bortezomib or RIT alone in MCL. ${ }^{61}$ Thus, more investigation of therapeutic combinations of Y 90 ibritumomab tiuxetan and targeted therapeutics is warranted in relapsed/refractory MCL.

Overall, RIT appears to have activity in aggressive subtypes of NHL, particularly as part of a consolidation regimen after short-course chemotherapy. However, a relative paucity of data exists for these indications, especially in regard to comparison with current chemoimmunotherapy regimens and novel targeted therapeutic strategies, so further investigation of these entities is needed before RIT can become part of the standard of care.

\section{As a preparative regimen prior to high-dose therapy and hematopoietic stem cell transplantation}

One of the most exciting recent developments in the field of RIT for NHL has been the investigation of Y90 ibritumomab tiuxetan in preparative regimens prior to hematopoietic stem cell transplantation. High-dose chemotherapy (HDCT) and hematopoietic stem cell transplantation results in durable disease-free survival in a subset of NHL patients and is an important modality in the treatment of both indolent and aggressive NHL. HDCT and autologous stem cell transplantation (ASCT) at relapse improve progression-free survival as well as overall survival in chemoresponsive patients, and the probability of relapse at the time of long-term follow-up appears to be significantly correlated with achievement of CR after transplant. ${ }^{62-64} \mathrm{ASCT}$ was previously widely performed with a preparative regimen including total body irradiation (TBI), which takes advantage of the radiosensitivity of NHL, but this approach has become much less common recently given concerns over the added long-term risk of secondary malignancies after TBI-based regimens. ${ }^{62,65,66}$ As compared with TBI, RIT offers a targeted method of delivering radiotherapy to CD20+ NHL, which better balances toxicity with the benefits of radiation. Additionally, as stem cell infusion in the setting of hematopoietic stem cell transplantation can negate the hematologic toxicity of Y 90 ibritumomab, it can be administered in the setting of bone marrow transplantation with very little toxicity.

Strategies using Y90 ibritumomab at myeloablative doses alone as well as in addition to standard HDCT have been studied and continue to be investigated as innovative treatments for NHL, most often with ASCT. The simplest approach to stem cell transplantation utilizing Y 90 
ibritumomab in NHL is the administration of myeloablative doses of RIT followed by stem cell rescue. Such a strategy used with the initial report of CD20-targeted RIT and dose escalation with stem cell support using non-hematopoietic toxicity and dosimetry data established $1.2 \mathrm{mCi} / \mathrm{kg}$ as the maximum tolerated Y90 ibritumomab dose. This dosing was evaluated in an Italian trial that enrolled 60 patients with relapsed/refractory or high-risk NHL and reported a CR rate of $90 \%$, with 5-year progression-free survival and overall survival rates of $62.7 \%$ and $72.9 \%$, respectively, and a 5-year relapse rate of $32.5 \% .{ }^{67,68}$ Toxicities were manageable in this study, with a non-relapse mortality of $1.2 \%$. Notably, all the patients enrolled in this study were deemed ineligible by their primary treating physician for HDCT/ASCT. Thus, myeloablative Y90 ibritumomab preparative dosing regimens may be an effective method to allow patients to undergo a potentially curative transplant even when they are unable to tolerate conventional HDCT. This could be a particularly valuable strategy in this population, given that outcomes are poor with standard-dose chemotherapy and this patient group has few established treatment options. High-dose Y90 ibritumomab can also be added to standard HDCT with very little added toxicity; two published trials have evaluated this strategy using a dosimetric approach in patients with NHL. Nademanee et al completed a Phase I/II trial of indium-111 ibritumomab tiuxetan infusion on day 21 followed by Y90 ibritumomab infusion dosed to achieve a maximum of 1,000 cGy to normal organs. ${ }^{69}$ A median total dose of 71.6 (range 36.6-105) $\mathrm{mCi}$ was delivered, followed by etoposide $60 \mathrm{mg}$ / $\mathrm{kg}$ and cyclophosphamide $100 \mathrm{mg} / \mathrm{kg}$ on days -4 and -2 , respectively. A total of 31 patients were treated in this study, and $12 / 13$ patients with active disease prior to treatment achieved a CR. The 2-year progression-free survival and overall survival rates were $78 \%$ and $92 \%$, respectively, with manageable toxicities. Another trial using high-dose Y90 ibritumomab evaluated up to 1,700 cGy delivered to normal organs in combination with BEAM (rituximab/carmustine, etoposide, cytarabine, and melphalan) chemotherapy in 44 patients with relapsed/refractory NHL.${ }^{70}$ In this study, 3-year progression-free survival and overall survival rates were $43 \%$ and $60 \%$, respectively, and median time to progression was estimated to be 20 months. Toxicities with this approach were similar to those expected with chemotherapy given without the addition of RIT.

In all three of the above studies, bone marrow engraftment occurred at the expected time points, with median times of 7-10 and 12-21 days for neutrophil and platelet engraftment, respectively. Thus, high-dose/myeloablative
Y90 ibritumomab has been shown to be tolerable in multiple studies, with toxicities and times to bone marrow recovery comparable with those experienced with high-dose chemotherapy alone.

The addition of standard-dose Y90 ibritumomab tiuxetan $(0.4 \mathrm{mCi} / \mathrm{kg})$ to standard autologous transplantation conditioning chemotherapy has also been found to have encouraging efficacy, durability, and tolerability in salvage therapy for relapsed/refractory indolent and aggressive NHL in at least a half dozen published Phase I/II studies performed at multiple centers. ${ }^{71-76}$ As with the use of myeloablative RIT prior to ASCT, this strategy is feasible, with toxicities and engraftment patterns similar to historical experience with preparative chemotherapy alone. Progression-free survival and overall survival at short-term follow-up (2-4 years) ranged from $52 \%$ to $80 \%$ and from $26.3 \%$ to $97 \%$, respectively, in these studies, with variations in outcome seen between patients of differing risk strata and residual disease at time of HDCT/ ASCT/RIT. Overall, while these results are encouraging, given the non-randomized nature of these data, the diverse subtypes of NHL treated, and variations in the high-dose preparative regimens used, it is difficult to deduce whether the addition of Y90 ibritumomab improves outcomes with HDCT/ASCT approaches.

Three studies have approached this problem with matched cohort and randomized studies. At the City of Hope National Medical Center, Krishnan et al conducted a matched-cohort analysis of TBI-based HDCT/ASCT versus Y90 ibritumomab added to BEAM (Z-BEAM) in 92 patients with relapsed/refractory or high-risk international prognostic index score at diagnosis. ${ }^{77}$ Patients in the Z-BEAM group underwent indium-111 imaging on day 21 followed by Y90 ibritumomab on day -14 and ASCT after BEAM chemotherapy; patients in the TBI-HDCT cohort underwent ASCT after 1,200 cGy radiation given on days -8 to -6 and etoposide $40 \mathrm{mg} / \mathrm{kg}$ and cyclophosphamide $100 \mathrm{mg} / \mathrm{kg}$ on days -4 and -2 , respectively. There were significantly more grade 3-4 toxicities in the TBI group, which consisted primarily of infections and mucositis and at least three deaths related to therapy versus none with Z-BEAM treatment. Notably, significantly better overall survival at 4 years was noted in the Z-BEAM cohort versus those receiving TBI ( $81 \%$ versus $52.7 \%$, respectively, $P=0.01$ ) and there was a trend towards improved 4 year progression-free survival with Z-BEAM (59.6\% versus $42 \%, P=0.1$ ) with lower nonrelapse mortality in the Z-BEAM group. Thus, the results of this study indicate that standard-dose RIT added to HDCT is more efficacious and tolerable than TBI-based preparative 
regimens prior to ASCT, in particular because of higher non-relapse-associated mortality rates with TBI.

Different results were found in the Nordic MCL3 study, which used a similar trial design and analysis in $160 \mathrm{MCL}$ patients treated with five cycles of induction chemotherapy followed by positron emission tomography-computed tomography assessment of response and planned BEAM or BEAC (carmustine, etoposide, cytarabine) conditioning and ASCT. ${ }^{78}$ Y90 ibritumomab $(0.4 \mathrm{mCi} / \mathrm{kg})$ was added to the preparative regimen in patients with less than a CR by Deauville criteria at the time of assessment by positron emission tomography-computed tomography. Results were then compared with a historical control from the MCL2 trial, which enrolled patients with almost identical baseline characteristics to those in the MCL3 trial, but did not incorporate Y90 ibritumomab into HDCT/ASCT consolidation. In the MCL2 trial, 64/67 patients who did not achieve a CR after induction chemotherapy went on to receive RIT as planned. However, addition of RIT did not improve outcomes when compared with those in the MCL2 trial. Median event-free survival, progression-free survival, and overall survival rates were the same in both studies for the entire cohort as well as for the subgroup that did not obtain a CR after induction chemotherapy, demonstrating that addition of RIT did not seem to improve outcomes.

A small randomized study of Y90 ibritumomab tiuxetan plus BEAM conditioning versus BEAM conditioning alone in 43 patients with relapsed/refractory NHL found no difference in 2-year progression-free survival (59\% versus 37\%, $P=0.2$ ), but there was an improvement in 2-year overall survival in the Y90 ibritumomab tiuxetan + BEAM group (91\% versus $62 \%, P=0.05) .{ }^{79}$ An ongoing Phase III study is evaluating this strategy in an expanded cohort, and will hopefully provide a definitive answer about the role of RIT in ASCT.

Several groups have also reported on allogeneic transplantation after Y90 ibritumomab tiuxetan-containing conditioning regimens, ${ }^{80-84}$ but these data are largely limited to single-institution experience. Overall, encouraging results have been seen in these studies, and this is an approach deserving of further study in relapsed/refractory and high-risk NHL.

Y90 ibritumomab can be added to myeloablative regimens in high-risk or relapsed/refractory NHL, with very little added toxicity and encouraging outcomes in selected patients. Further analysis of the utility of this strategy in autologous and allogeneic treatment regimens for NHL is an exciting frontier in the investigation of novel therapeutics for these diseases, and will continue to be a focus of active study in the coming years.

\section{Current role in RIT for NHL}

Even though Y90 ibritumomab tiuxetan has been evaluated in hundreds of studies in CD20+ NHL and has two indications approved by the FDA, its role in the treatment of patients with newly diagnosed or relapsed/refractory lymphoma is unclear. This uncertainty has been reflected in a perceived underuse of RIT by oncologists, which may have ultimately led to the recent withdrawal of $\mathrm{I}^{131}$-tositumomab, another RIT agent, from commercial sales. The reluctance of oncologists to prescribe Y90 ibritumomab tiuxetan for NHL indications may be better explored by discussion and synthesis of the data previously mentioned.

Several technical and logistic obstacles exist with regard to administration of Y90 ibritumomab tiuxetan, and are major hurdles to its implementation. RIT requires careful handling and nuclear medicine expertise, which often exists only in tertiary referral centers. Likewise, dosimetry has historically been required to dose RIT, and this has limited its use to centers with nuclear medicine expertise. Although dosimetry is no longer required, infrequent prescribers of the drug may not be aware of the change. As a single infusion, Y90 ibritumomab tiuxetan is also very expensive $(>\$ 40,000$ USD), ${ }^{85}$ but is comparable with other anti-CD20 antibody approaches when considering one infusion of RIT to be an entire treatment course whereas multiple infusions of rituximab would be needed at a similar total cost for a course of treatment. Considering that multiple cycles of combination chemotherapy with rituximab are often chosen for initial and salvage treatment of follicular lymphoma and other NHLs, the cost of RIT seems more reasonable. ${ }^{86}$ Nevertheless, the upfront cost of RIT and logistic difficulties in its administration may result in negative attitudes toward its clinical use in NHL.

Critical appraisal of the evidence base for use of Y90 ibritumomab tiuxetan also sheds light on some of the difficulties the oncology community has had in incorporating it into treatment schemes for NHL. A major impediment is that much of the data on RIT are compared with or added to nonrituximab-containing regimens, which are no longer a standard of care. Therefore, it is difficult to determine the role of RIT and its efficacy when given to patients previously treated with rituximab-containing regimens. In the front-line setting, Y90 ibritumomab tiuxetan has been shown to have excellent activity in follicular lymphoma, but no clinical trials have reported response rates, progression-free survival, or overall 
survival comparisons with standard chemoimmunotherapy induction schemes, such as R-CVP or R-CHOP with or without CD20-targeted maintenance approaches. Because the existing data on RIT as sole upfront therapy come from Phase II studies, it is difficult to draw conclusions as to the role of RIT in induction treatment for follicular lymphoma. Also, indolent NHL is often now treated with new upfront approaches, such as rituximab-bendamustine combinations, ${ }^{87}$ that may further prolong progression-free survival in indolent NHL compared with R-CVP or anthracycline-containing programs which were not widely used when the completed studies of RIT were designed.

Studies of Y90 ibritumomab tiuxetan as a consolidation strategy in patients with chemotherapy-responsive follicular lymphoma have shown significant clinical activity, with impressive rates of $\mathrm{CR} / \mathrm{Cru}$ conversion and improved progression-free survival. However, each of these studies suffers from significant flaws and potential biases that limit the ability to draw conclusions in favor of RIT consolidation using Y90 ibritumomab tiuxetan. Addition of Y90 ibritumomab tiuxetan consolidation has not been well studied in a population of patients treated with current standard chemotherapy/rituximab combinations such as R-CHOP or R-bendamustine. ${ }^{87}$ In FIT, only $14 \%$ of patients received rituximab, so adequate statistical power to detect a difference between rituximab-treated patients randomized to Y90 ibritumomab tiuxetan versus observation was not reached. Two of the three other Phase II studies evaluating Y90 ibritumomab tiuxetan for this indication did use rituximab in preconsolidation treatment but by design did not have comparator arms. Additionally, at present, given the popularity of rituximab maintenance schemes, the data regarding Y90 ibritumomab tiuxetan consolidation in follicular lymphoma must be considered in light of the fact that rituximab maintenance may narrow the difference between RIT consolidation and standard therapy. A hint of this notion can be gleaned from the Southwest Oncology Group S0016 trial that compared initial treatment of follicular lymphoma using CHOP followed by $\mathrm{I}^{131}$-tositumomab against initial R-CHOP alone and found no differences in progression-free survival $(80 \%$ versus $76 \%, P=0.11$ ) or overall survival ( $97 \%$ versus $93 \%$, $P=0.08) .{ }^{88}$ Thus, it is unclear what the role of RIT should play in the front-line treatment of indolent NHL. Randomized controlled trials using updated initial treatment strategies as comparators against RIT front-line and consolidation therapy are needed.

Y90 ibritumomab tiuxetan RIT has been best studied in relapsed/refractory or transformed NHL, and is an attractive agent for this indication, given its unique mechanism of cytotoxicity and potential for avoiding cross-resistance to chemotherapeutics. One consideration in the treatment of patients with relapsed/refractory disease is the timing of onset and recovery from RIT-associated cytopenias. Given that neutropenia and thrombocytopenia occur relatively further out from RIT than cytotoxic chemotherapy (4-6 weeks post infusion), delayed cytopenias from RIT may make subsequent cycles of palliative chemotherapy more difficult to administer in the face of rapidly progressing symptomatic disease. Additionally, RIT appears less effective and potentially more toxic in more heavily pretreated patients, and it is unclear what benefit Y90 ibritumomab tiuxetan may offer in multiply relapsed NHL patients over any given salvage regimen administered with or without consolidative stem cell transplantation.

The use of Y90 ibritumomab as part of the preparative regimen prior to stem cell transplant is the most exciting area of ongoing research. RIT preparative regimens may be less toxic than traditional TBI-based regimens, and may open the door for less fit patients to successfully undergo potentially curative ASCT. Ultimately, more rigorous investigation is needed to define the benefit of these strategies over conventional HDCT/ASCT and/or allogeneic stem cell transplant alone, and these studies are ongoing.

Lastly, the concern about a possible increased incidence of MDS/AML after RIT may make oncologists cautious about using it. This may particularly be true in the front-line setting when a multitude of other therapeutic options are available.

A number of limitations thus exist to explain the lack of more widespread use of Y90 ibritumomab tiuxetan for NHL. However, application of these data to the practical treatment of NHL reveals a number of opportunities for the use of RIT and for future study. In the front-line setting, one rational approach would be to use RIT in tandem with front-line strategies including rituximab/chemotherapy combinations or with newer agents such as bendamustine. This strategy maintains the benefit of rituximab early on in therapy and likely has long-term progression-free survival and treatment-free intervals at least similar to those of rituximab-based maintenance schemes. In relapsed/refractory disease, RIT appears to be best suited for use as an early salvage regimen in patients with a low disease burden. Ultimately, it may become a standard part of induction therapy prior to stem cell transplant. Y90 ibritumomab tiuxetan also has potential in combination with novel molecular targeted therapies in relapsed/refractory disease and should be investigated in this setting. 


\section{Conclusion}

RIT with Y90 ibritumomab tiuxetan is a unique and efficacious treatment modality with activity across the spectrum of NHL subtypes and at various phases of treatment. Front-line and relapsed follicular lymphomas are the two clinical indications for which FDA approval has been granted. Other clinical trials have examined Y90 ibritumomab tiuxetan in other disease types alone and in combination with chemotherapy, hematopoietic stem cell transplantation, and novel small molecular inhibitor therapies. Overall, RIT including Y90 ibritumomab tiuxetan is an exciting approach to the treatment of NHL, but a lack of randomized controlled Phase III trials limits the ability to draw conclusions regarding the role of RIT in the rituximab era.

\section{Disclosure}

The authors report no conflicts of interest in this work.

\section{References}

1. Siegel R, Naishadham D, Jemal A. Cancer statistics, 2012. CA Cancer J Clin. 2012;62(1):10-29.

2. Hennessy BT, Hanrahan EO, Daly PA. Non-Hodgkin lymphoma: an update. Lancet Oncol. 2004;5(6):341-353.

3. Swerdlow SH, Campo E, Harris NL, et al. WHO Classification of Tumours of Haematopoietic and Lymphoid Tissues. 4th ed. Lyon, France: IARC Press; 2008.

4. Gallagher CJ, Gregory WM, Jones AE, et al. Follicular lymphoma: prognostic factors for response and survival. J Clin Oncol. 1986;4(10): 1470-1480.

5. Coiffier B, Lepage E, Briere J, et al. CHOP chemotherapy plus rituximab compared with $\mathrm{CHOP}$ alone in elderly patients with diffuse large-B-cell lymphoma. N Engl J Med. 2002;346(4):235-242.

6. Lenz G, Wright G, Dave SS, et al. Stromal gene signatures in large-Bcell lymphomas. N Engl J Med. 2008;359(22):2313-2323.

7. Zhou Z, Sehn LH, Rademaker AW, et al. An enhanced International Prognostic Index (NCCN-IPI) for patients with diffuse large B-cell lymphoma treated in the rituximab era. Blood. 2014;123(6):837-842.

8. O'Mahony D, Bishop MR. Monoclonal antibody therapy. Front Biosci. 2006;11:1620-1635.

9. Maloney DG, Liles TM, Czerwinski DK, et al. Phase I clinical trial using escalating single-dose infusion of chimeric anti-CD20 monoclonal antibody (IDEC-C2B8) in patients with recurrent B-cell lymphoma Blood. 1994;84(8):2457-2466

10. Maloney DG, Grillo-López AJ, White CA, et al. IDEC-C2B8 (rituximab) anti-CD20 monoclonal antibody therapy in patients with relapsed low-grade non-Hodgkin's lymphoma. Blood. 1997;90(6) 2188-2195.

11. Coiffier B, Lepage E, Briere J, et al. CHOP chemotherapy plus rituximab compared with CHOP alone in elderly patients with diffuse large-B-cell lymphoma. N Engl J Med. 2002;346(4):235-242.

12. Hiddemann W, Kneba M, Dreyling M, et al. Frontline therapy with rituximab added to the combination of cyclophosphamide, doxorubicin, vincristine, and prednisone (CHOP) significantly improves the outcome for patients with advanced-stage follicular lymphoma compared with therapy with CHOP alone: results of a prospective randomized study of the German Low-Grade Lymphoma Study Group. Blood. 2005;106(12): 3725-3732.

13. Kluin-Nelemans HC, Hoster E, Hermine O, et al. Treatment of older patients with mantle-cell lymphoma. N Engl J Med. 2012;367(6): 520-531.
14. van Oers MH, Klasa R, Marcus RE, et al. Rituximab maintenance improves clinical outcome of relapsed/resistant follicular non-Hodgkin lymphoma in patients both with and without rituximab during induction: results of a prospective randomized phase 3 intergroup trial. Blood. 2006;108(10):3295-3301.

15. Peters MV. The contribution of radiation therapy in the control of early lymphomas. Am J Roentgenol Radium Ther Nucl Med. 1963;90: 956-967.

16. Juweid ME. Radioimmunotherapy of B-cell non-Hodgkin's lymphoma: from clinical trials to clinical practice. J Nucl Med. 2002;43(11):1507-1529.

17. Grillo-Lopez AJ. Zevalin: the first radioimmunotherapy approved for the treatment of lymphoma. Expert Rev Anticancer Ther. 2002;2(5): 485-493.

18. Wiseman GA, White CA, Sparks RB, et al. Biodistribution and dosimetry results from a phase III prospectively randomized controlled trial of Zevalin radioimmunotherapy for low-grade, follicular, or transformed B-cell non-Hodgkin's lymphoma. Crit Rev Oncol Hematol. 2001;39(1-2):181-194.

19. Wagner HN, Wiseman GA, Marcus CS, et al. Administration guidelines for radioimmunotherapy of non-Hodgkin's lymphoma with (90) Y-labeled anti-CD20 monoclonal antibody. J Nucl Med. 2002;43(2): 267-272.

20. Wiseman GA, Leigh B, Erwin WD, et al. Radiation dosimetry results for Zevalin radioimmunotherapy of rituximab-refractory non-Hodgkin lymphoma. Cancer. 2002;94(Suppl 4):1349-1357.

21. Wiseman GA, Kornmehl E, Leigh B, et al. Radiation dosimetry results and safety correlations from 90 Y-ibritumomab tiuxetan radioimmunotherapy for relapsed or refractory non-Hodgkin's lymphoma: combined data from 4 clinical trials. J Nucl Med. 2003;44(3):465-474.

22. Knox SJ, Goris ML, Trisler K, et al. Yttrium-90-labeled anti-CD20 monoclonal antibody therapy of recurrent B-cell lymphoma. Clin Cancer Res. 1996;2(3):457-470.

23. Witzig TE, White CA, Wiseman GA, et al. Phase I/II trial of IDECY2B8 radioimmunotherapy for treatment of relapsed or refractory CD20(+) B-cell non-Hodgkin's lymphoma. J Clin Oncol. 1999;17(12): 3793-3803.

24. Wiseman GA, Gordon LI, Multani PS, et al. Ibritumomab tiuxetan radioimmunotherapy for patients with relapsed or refractory nonHodgkin lymphoma and mild thrombocytopenia: a phase II multicenter trial. Blood. 2002;99(12):4336-4342.

25. Guidetti A, Carlo-Stella C, Ruella M, et al. Myeloablative doses of yttrium-90-ibritumomab tiuxetan and the risk of secondary myelodysplasia/acute myelogenous leukemia. Cancer. 2011;117(22): 5074-5084.

26. Hohloch K, Zinzani PL, Linkesch W, et al. Radioimmunotherapy with (90)Y-ibritumomab tiuxetan is a safe and efficient treatment for patients with B-cell lymphoma relapsed after auto-SCT: an analysis of the international RIT-network. Bone Marrow Transplant. 2011;46(6): 901-903.

27. Ansell SM, Ristow KM, Habermann TM, Wiseman GA, Witzig TE. Subsequent chemotherapy regimens are well tolerated after radioimmunotherapy with yttrium-90 ibritumomab tiuxetan for non-Hodgkin's lymphoma. J Clin Oncol. 2002;20(18):3885-3890.

28. Czuczman MS, Emmanouilides C, Darif M, et al. Treatment-related myelodysplastic syndrome and acute myelogenous leukemia in patients treated with ibritumomab tiuxetan radioimmunotherapy. J Clin Oncol. 2007;25(7):4285-4292.

29. Morschhauser F, Radford J, Van Hoof A, et al. 90Yttrium-ibritumomab tiuxetan consolidation of first remission in advanced-stage follicular non-Hodgkin lymphoma: updated results after a median follow-up of 7.3 years from the international, randomized, phase III first-line indolent trial. J Clin Oncol. 2013;31(16):1977-1983.

30. Ghielmini M, Schmitz SF, Cogliatti SB, et al. Prolonged treatment with rituximab in patients with follicular lymphoma significantly increases event-free survival and response duration compared with the standard weekly $\times 4$ schedule. Blood. 2004;103(12):4416-4423. 
31. Hainsworth JD, Litchy S, Shaffer DW, Lackey VL, Grimaldi M, Greco FA. Maximizing therapeutic benefit of rituximab: maintenance therapy versus re-treatment at progression in patients with indolent nonHodgkin's lymphoma - a randomized phase II trial of the Minnie Pearl Cancer Research Network. J Clin Oncol. 2005;23(6):1088-1095.

32. Morschhauser F, Radford J, Van Hoof A, et al. Phase III trial of consolidation therapy with yttrium-90-ibritumomab tiuxetan compared with no additional therapy after first remission in advanced follicular lymphoma. J Clin Oncol. 2008;26(32):5156-5164.

33. Scholz CW, Pinto A, Linkesch W, et al. (90)Yttrium-ibritumomabtiuxetan as first-line treatment for follicular lymphoma: 30 months of follow-up data from an international multicenter phase II clinical trial. J Clin Oncol. 2013;31(3):308-313.

34. Illidge TM, Mayes S, Pettengell R, et al. Fractionated (9)(0) Y-ibritumomab tiuxetan radioimmunotherapy as an initial therapy of follicular lymphoma: an international phase II study in patients requiring treatment according to GELF/BNLI criteria. J Clin Oncol. 2014;32(3):212-218.

35. Cicone F, Russo E, Carpaneto A, et al. Follicular lymphoma at relapse after rituximab containing regimens: comparison of time to event intervals prior to and after 90 Y-ibritumomab-tiuxetan. Hematol Oncol. 2011;29(3):131-138.

36. Wiseman GA, Leigh BR, Erwin WD, et al. Radiation dosimetry results from a Phase II trial of ibritumomab tiuxetan (Zevalin) radioimmunotherapy for patients with non-Hodgkin's lymphoma and mild thrombocytopenia. Cancer Biother Radiopharm. 2003;18(2): $165-178$.

37. Witzig TE, Molina A, Gordon LI, et al. Long-term responses in patients with recurring or refractory B-cell non-Hodgkin lymphoma treated with yttrium 90 ibritumomab tiuxetan. Cancer. 2007;109(9):1804-1810.

38. Witzig TE, Flinn IW, Gordon LI, et al. Treatment with ibritumomab tiuxetan radioimmunotherapy in patients with rituximab-refractory follicular non-Hodgkin's lymphoma. J Clin Oncol. 2002;20(15): 3262-3269.

39. Witzig TE, Gordon LI, Cabanillas F, et al. Randomized controlled trial of yttrium-90-labeled ibritumomab tiuxetan radioimmunotherapy versus rituximab immunotherapy for patients with relapsed or refractory low-grade, follicular, or transformed B-cell non-Hodgkin's lymphoma. J Clin Oncol. 2002;20(10):2453-2463.

40. Gordon LI, Witzig T, Molina A, et al. Yttrium 90-labeled ibritumomab tiuxetan radioimmunotherapy produces high response rates and durable remissions in patients with previously treated B-cell lymphoma. Clin Lymphoma. 2004;5(2):98-101.

41. Shah J, Wang W, Harrough VD, et al. Retreatment with yttrium-90 ibritumomab tiuxetan in patients with B-cell non-Hodgkin's lymphoma. Leuk Lymphoma. 2007;48(9):1736-1744.

42. Cronin-Fenton DP, Sharp L, Deady S, Comber H. Treatment and survival for non-Hodgkin's lymphoma: influence of histological subtype, age, and other factors in a population-based study (1999-2001). Eur J Cancer. 2006;42(16):2786-2793.

43. Han X, Kilfoy B, Zheng T, et al. Lymphoma survival patterns by WHO subtype in the United States, 1973-2003. Cancer Causes Control. 2008;19(8):841-858.

44. Fisher RI, Dahlberg S, Nathwani BN, Banks PM, Miller TP, Grogan TM. A clinical analysis of two indolent lymphoma entities: mantle cell lymphoma and marginal zone lymphoma (including the mucosaassociated lymphoid tissue and monocytoid B-cell subcategories): a Southwest Oncology Group study. Blood. 1995;85(4): 1075-1082.

45. Morschhauser F, Illidge T, Huglo D, et al. Efficacy and safety of yttrium-90 ibritumomab tiuxetan in patients with relapsed or refractory diffuse large B-cell lymphoma not appropriate for autologous stem-cell transplantation. Blood. 2007;110(1):54-58.

46. Zinzani PL, Rossi G, Franceschetti S, et al. Phase II trial of short-course R-CHOP followed by 90 Y-ibritumomab tiuxetan in previously untreated high-risk elderly diffuse large B-cell lymphoma patients. Clin Cancer Res. 2010;16(15):3998-4004.
47. Zinzani PL, Tani M, Fanti S, et al. A phase II trial of CHOP chemotherapy followed by yttrium 90 ibritumomab tiuxetan (Zevalin) for previously untreated elderly diffuse large B-cell lymphoma patients. Ann Oncol. 2008;19(4):769-773.

48. Yang DH, Kim WS, Kim SJ, et al. Pilot trial of yttrium-90 ibritumomab tiuxetan consolidation following rituximab, cyclophosphamide, doxorubicin, vincristine and prednisolone chemotherapy in patients with limited-stage, bulky diffuse large B-cell lymphoma. Leuk Lymphoma. 2012;53(5):807-811.

49. Smith MR, Li H, Gordon L, et al. Phase II study of rituximab plus cyclophosphamide, doxorubicin, vincristine, and prednisone immunochemotherapy followed by yttrium-90-ibritumomab tiuxetan in untreated mantle-cell lymphoma: Eastern Cooperative Oncology Group Study E1499. J Clin Oncol. 2012;30(25):3119-3126.

50. Arranz R, García-Noblejas A, Grande C, et al. First line treatment with rituximab-hyper-CVAD alternating with rituximab-methotrexatecytarabine and followed by consolidation with 90Y-IbritumomabTiuxetan in patients with mantle cell lymphoma. Results of a phase 2 pilot multicenter trial from the GELTAMO group. Haematologica. 2013;98(10):1563-1570.

51. Wang M, Oki Y, Pro B, et al. Phase II study of yttrium-90-ibritumomab tiuxetan in patients with relapsed or refractory mantle cell lymphoma. J Clin Oncol. 2009;27(31):5213-5218.

52. Wang ML, Rule S, Martin P, et al. Targeting BTK with ibrutinib in relapsed or refractory mantle-cell lymphoma. $N$ Engl $J$ Med. 2013;369(6):507-516.

53. [No authors listed]. Ibrutinib approved for mantle cell lymphoma. Cancer Discov. 2014;4(1):OF1.

54. Habermann TM, Lossos IS, Justice G, et al. Lenalidomide oral monotherapy produces a high response rate in patients with relapsed or refractory mantle cell lymphoma. Br J Hematol. 2009;145(3): 344-349.

55. Tempescul A, Ianotto JC, Morel F, Marion V, De Braekeleer M, Berthou C. Lenalidomide, as a single agent, induces complete remission in a refractory mantle cell lymphoma. Ann Hematol. 2009;88(9):921-922.

56. Goy A, Sinha R, Williams ME, et al. Single-agent lenalidomide in patients with mantle-cell lymphoma who relapsed or progressed after or were refractory to bortezomib: phase II MCL-001 (EMERGE) study. J Clin Oncol. 2013;31(29):3688-3695.

57. Zinzani PL, Vose M, Czuczman MS, et al. Long-term follow-up of lenalidomide in relapsed/refractory mantle cell lymphoma: subset analysis of the NHL-003 study. Ann Oncol. 2013;24(11): 2892-2897.

58. Goy A, Younes A, McLaughlin P, et al. Phase II study of proteasome inhibitor bortezomib in relapsed or refractory B-cell non-Hodgkin's lymphoma. J Clin Oncol. 2005;23(4):667-675.

59. O'Connor OA, Wright J, Moskowitz C, et al. Phase II clinical experience with the novel proteasome inhibitor bortezomib in patients with indolent non-Hodgkin's lymphoma and mantle cell lymphoma. J Clin Oncol. 2005;23(4):676-684.

60. Kane RC, Dagher R, Farrell A, et al. Bortezomib for the treatment of mantle cell lymphoma. Clin Cancer Res. 2007;13(18 Pt 1): 5291-5294.

61. Beaven AW, Shea TC, Moore DT, et al. A phase I study evaluating ibritumomab tiuxetan (Zevalin $\left.{ }^{\circledR}\right)$ in combination with bortezomib (Velcade ${ }^{\circledR}$ ) in relapsed/refractory mantle cell and low grade B-cell non-Hodgkin lymphoma. Leuk Lymphoma. 2013;53(2): 254-258.

62. Philip T, Guglielmi C, Hagenbeek A, et al. Autologous bone marrow transplantation as compared with salvage chemotherapy in relapses of chemotherapy-sensitive non-Hodgkin's lymphoma. $N$ Engl J Med. 1995;333(23):1540-1545

63. Schouten HC, Qian W, Kvaloy S, et al. High-dose therapy improves progression-free survival and survival in relapsed follicular nonHodgkin's lymphoma: results from the randomized European CUP trial. J Clin Oncol. 2003;21(21):3918-3927. 
64. Sebban C, Brice P, Delarue R, et al. Impact of rituximab and/or high-dose lymphoma: a GELA study. J Clin Oncol. 2008;26(21):3614-3620.

65. Brown JR, Yeckes H, Friedberg JW, et al. Increasing incidence of late second malignancies after conditioning with cyclophosphamide and total-body irradiation and autologous bone marrow transplantation for non-Hodgkin’s lymphoma. J Clin Oncol. 2005;23(10):2208-2214.

66. Sebban C, Mounier N, Brousse N, et al. Standard chemotherapy with interferon compared with CHOP followed by high-dose therapy with autologous stem cell transplantation in untreated patients with advanced follicular lymphoma: the GELF-94 randomized study from the Groupe d'Etude des Lymphomes de l'Adulte (GELA). Blood. 2006;108(8):2540-2544.

67. Devizzi L, Guidetti A, Tarella C, et al. High-dose yttrium-90ibritumomab tiuxetan with tandem stem-cell reinfusion: an outpatient preparative regimen for autologous hematopoietic cell transplantation. J Clin Oncol. 2008;26(32):5175-5182.

68. Devizzi L, Guidetti A, Seregni E, et al. Long-term results of autologous hematopoietic stem-cell transplantation after high-dose 90 Y-ibritumomab tiuxetan for patients with poor-risk non-Hodgkin lymphoma not eligible for high-dose BEAM. J Clin Oncol. 2012;31(23): 2974-2976.

69. Nademanee A, Forman S, Molina A, et al. A phase 1/2 trial of highdose yttrium-90-ibritumomab tiuxetan in combination with high-dose etoposide and cyclophosphamide followed by autologous stem cell transplantation in patients with poor-risk or relapsed non-Hodgkin lymphoma. Blood. 2005;106(8):2896-2902.

70. Winter JN, Inwards DJ, Spies S, et al. Yttrium-90 ibritumomab tiuxetan doses calculated to deliver up to 15 Gy to critical organs may be safely combined with high-dose BEAM and autologous transplantation in relapsed or refractory B-cell non-Hodgkin's lymphoma. J Clin Oncol. 2009;27(10):1653-1659.

71. Han EJ, Lee SE, Kim SH, et al. Clinical outcomes of post-remission therapy using (90)yttrium ibritumomab tiuxetan $\left(\right.$ Zevalin $\left.^{\circledR}\right)$ for high-risk patients with diffuse large B-cell lymphoma. Ann Hematol. 2011;90(9): 1075-1082.

72. Kang BW, Kim WS, Kim C, et al. Yttrium-90-ibritumomab tiuxetan in combination with intravenous busulfan, cyclophosphamide, and etoposide followed by autologous stem cell transplantation in patients with relapsed or refractory B-cell non-Hodgkin's lymphoma. Invest New Drugs. 2010;28(4):516-522.

73. Wondergem MJ, Zijlstra JM, de Rooij M, Visser OJ, Huijgens PC, Zweegman S. Improving survival in patients with transformed B cell non Hodgkin lymphoma: consolidation with ${ }^{90}$ Yttrium ibritumomab tiuxetan-BEAM and autologous stem cell transplantation. Br J Haematol. 2012;157(3):395-397.

74. Krishnan A, Nandemanee A, Fung HC, et al. Phase II trial of a transplantation regimen of yttrium-90 ibritumomab tiuxetan and high-dose chemotherapy in patients with non-Hodgkin's lymphoma. J Clin Oncol. 2008;26(1):90-95.

75. Shimoni A, Zwas ST, Oksman Y, et al. Yttrium-90-ibritumomab tiuxetan (Zevalin) combined with high-dose BEAM chemotherapy and autologous stem cell transplantation for chemo-refractory aggressive non-Hodgkin's lymphoma. Exp Hematol. 2007;35(4):534-540.

76. Decaudin D, Mounier N, Tilly $\mathrm{H}$, et al. ${ }^{90} \mathrm{Y}$ ibritumomab tiuxetan (Zevalin) combined with BEAM (Z -BEAM) conditioning regimen plus autologous stem cell transplantation in relapsed or refractory low-grade CD20-positive B-cell lymphoma. A GELA phase II prospective study. Clin Lymphoma Myeloma Leuk. 2011;11(2):212-218. therapy with autotransplant at time of relapse in patients with follicular

77. Krishnan A, Palmer JM, Tsai NC, et al. Matched-cohort analysis of autologous hematopoietic cell transplantation with radioimmunotherapy versus total body irradiation-based conditioning for poor-risk diffuse large cell lymphoma. Biol Blood Marrow Transplant. 2012;18(3):441-450.

78. Kolstad A, Laurell A, Jerkeman M, et al. Nordic MCL3 study: 90Y-ibritumomab-tiuxetan added to BEAM/C in non-CR patients before transplant in mantle cell lymphoma. Blood. 2014;123(19): 2953-2959.

79. Shimoni A, Avivi I, Rowe JM, et al. A randomized study comparing yttrium-90 ibritumomab tiuxetan (Zevalin) and high-dose BEAM chemotherapy versus BEAM alone as the conditioning regimen before autologous stem cell transplantation in patients with aggressive lymphoma. Cancer. 2012;118(19):4706-4714.

80. Fietz T, Uharek L, Gentilini C, et al. Allogeneic hematopoietic cell transplantation following conditioning with 90Y-ibritumomab-tiuxetan. Leuk Lymphoma. 2006;47(1):59-63.

81. Gopal AK, Guthrie K, Rajendran J, et al. ${ }^{90}$ Y-Ibritumomab tiuxetan, fludarabine, and TBI-based nonmyeloablative allogeneic transplantation conditioning for patients with persistent high-risk B-cell lymphoma. Blood. 2011;118(4):1132-1139.

82. Abou-Nassar KE, Stevenson KE, Antin JH, et al. ${ }^{90}$ Y-ibritumomab tiuxetan followed by reduced-intensity conditioning and allo-SCT in patients with advanced follicular lymphoma. Bone Marrow Transplant. 2011;46(12):1503-1509.

83. Khouri IF, Saliba RM, Erwin WD, et al. Nonmyeloablative allogeneic transplantation with or without $90 y$ ttrium ibritumomab tiuxetan is potentially curative for relapsed follicular lymphoma: 12-year results. Blood. 2012;119(26):6373-6378.

84. Bethge WA, von Harsdorf S, Bornhauser M, et al. Dose-escalated radioimmunotherapy as part of reduced intensity conditioning for allogeneic transplantation in patients with advanced high-grade non-Hodgkin lymphoma. Bone Marrow Transplant. 2012;47(11):1397-1402.

85. Medicare Hospital Outpatient Prospective Payment System HOPPS (APC). SNM Advancing Molecular Imaging and Therapy. SNM Reimbursement Hospital Education Material. SNM Advancing Molecular Imaging and Therapy; 2011. Available from: http:// interactive.snm.org/docs/HOPPS\%202011F\%20vs\%202012F-Nov4-2011.pdf. Accessed July 3, 2014.

86. Johnston KM, Bolbocean C, Connors J, Peacock S. Cost-effectiveness of rituximab in follicular lymphoma. Exp Rev Pharmacoecon Outcomes Res. 2012;12(5):569-577.

87. Rummel MJ, Niederle N, Maschmeyer G, et al. Bendamustine plus rituximab versus $\mathrm{CHOP}$ plus rituximab as first-line treatment for patients with indolent and mantle-cell lymphomas: an open-label, multicentre, randomised, phase 3 non-inferiority trial. Lancet. 2013;381(9873): 1203-1210.

88. Press OW, Unger JM, Rimsza LM, et al. Phase III randomized intergroup trial of CHOP plus rituximab compared with CHOP chemotherapy plus (131) iodine-tositumomab for previously untreated follicular non-Hodgkin lymphoma: SWOG S0016. J Clin Oncol. 2013;31(3):314-320.

89. Tsimberidou AM, Murray JL, O’Brien S, Wierda WG, Keating MJ. Yttrium-90 ibritumomab tiuxetan radioimmunotherapy in Richter syndrome. Cancer. 2004;100(10):2195-2200.

\section{Dovepress}

\section{Publish your work in this journal}

Blood and Lymphatic Cancer: Targets and Therapy is an international, peer-reviewed, open access journal focusing on blood and lymphatic cancer research, identification of therapeutic targets and the optimal use of preventative and integrated treatment interventions to achieve improved outcomes, enhanced survival and quality of life for the cancer patient. The manuscript management system is completely online and includes a very quick and fair peer-review system. Visit http://www.dovepress.com/testimonials.php to read real quotes from published authors. 